\title{
As telas do sagrado ou o imaginário religioso da televisão
}

\author{
Jean-Jacques Wunenburger \\ Doutor; Université Jean Moulin Lyon III, Lyon, França \\ jean-jacques.wunenburger@wanadoo.fr \\ Tradução de Ana Taís Martins Portanova Barros \\ Pós-doutora; Universidade Federal do Rio Grande do Sul, Porto Alegre, RS, Brasil \\ anataisportanova@icloud.com
}

\section{Resumo}

Busca-se nesse artigo apresentar a hipótese de o sucesso da televisão advir de sua eficácia em tomar o lugar do religioso, consolidando-se como ponto de reencontro com o sagrado, mas sem um deus, antropocentrado: uma automanifestação. Essa hipótese é investigada por meio da metodologia filosófica. Conclui-se que, em vez de mobilizar a comunhão, característica da integração dos fenômenos religiosos, a televisão promove o isolamento, assemelhando-se a uma religião truncada, uma síntese de todas as experiências sagradas. Essa constatação contraria a suposta dessacralização propiciada pela técnica, engendrando uma paradoxal e simultânea ressacralização. As imagens na tela fazem reviver a hierofania do deus, das situações de possessão maléfica, de transformações de si no sentido de uma autodivinização.

\section{Palavras-chave}

Televisão. Imaginário. Religiosidade midiática. Ressacralização.

\section{Introdução}

$\mathrm{O}$ desenvolvimento mundial da televisão consagrou, desde a metade do século $\mathrm{XX}$, uma dominação sem precedentes da imagem artificial sobre a totalidade da cultura, marcando assim uma etapa absolutamente nova na história das relações dos homens com a esfera das imagens (esta "videosfera" que acaba de substituir a "grafosfera", segundo Régis Debray (1989). Se a imagem, em geral, constitui uma representação mental ou material que 
duplica o real, tornando possível sua reprodução no tempo e no espaço, até sua simulação, a imagem televisual constitui uma forma acabada de imagem. A imagem veiculada pela mídia "TV" atinge assim um estado extremo, uma forma total, antecipada desde a Antiguidade, na crítica platônica (PLATON, 2016) das imagens-simulacro, por exemplo. Sobre uma tela, pode-se seguir ao vivo um evento esportivo ou militar como se se estivesse lá, tocado pelas emoções reais enquanto se está imóvel em sua casa, esquecendo todas as mediações técnicas necessárias ao surgimento dessa "ilusão". Sobre a tela, o real do mundo aparece então como um simulacro particularmente bem sucedido, porque esta imagem, que toma o lugar da realidade aparente, foi gravada, trabalhada, controlada, emitida, difundida, recebida, projetada, vista ao preço de um complexo de encadeamento de intervenções especializadas, tornando-se, em certos aspectos, um fenômeno tecno-estético total.

Mas a TV faz mais do que cumprir a vocação da imagem, ela traz outras mudanças na esfera das imagens: uma verdadeira industrialização quanto à sua produção e difusão ou uma industrialização da cultura, no sentindo de Adorno e Horkheimer (1974). Além disso, a TV promove a captação-fagocitação de todos os outros regimes de imagem, já que o canal difunde um catálogo completo de tipos de imagens, instantâneos, quadros, fotografias, filmes etc. Também é possível aventar a proliferação dos espaços-tempos dedicados à observação, à imagem-ação, desde o registro de uma massa de eventos filmados até sua projeção repetitiva em todas as telas que são olhadas durante várias horas por dia. Através de círculos concêntricos, a TV engendra efeitos em cadeia no conjunto da sociedade contemporânea, no mundo financeiro, político, artístico, cultural. 0 sistema TV assegura mesmo todos os tipos de funções inéditas associando-se a práticas sociais mediatizadas de outro modo: diálogo interpessoal, opinião pública, erotismo privado, instrução pública, divertimentos populares, cultos religiosos etc.

Em função desse transbordamento e dessa diversificação impressionante, a TV não pode dar lugar a um discurso interpretativo único relativo a um objeto homogêneo, pois ela engloba uma rede e um fluxo sincrético de fenômenos imajados. Assim, ela resiste a uma teorização global e profunda, apesar do grande número de estudos pertinentes. Propõe-se, aqui, submetê-la a uma iluminação menos familiar, em relação com ritos e instituições mítico-religiosas tradicionais. De fato, não seria a TV um sucedâneo de fenômenos religiosos, ou o suporte e o teatro de uma nova religião, sem deus, antropocentrada, já que a imagem não serve mais um deus e sim é idolatrada nela mesma, um verdadeiro fetichismo? Apesar de diferenças não negligenciáveis, em primeiro lugar a privatização do rito e do 
consumo de imagens, a hipótese de uma religião da TV se revelaria frutuosa se se convocasse conjuntamente o religioso bem instituído, próprio a nossas religiões monoteístas, e as metamorfoses mais recentes do sagrado, absorvendo diferentes práticas mágicas.

\section{A tela sacralizadora do mundo}

No cotidiano, o fenômeno TV se reconhece antes de tudo pelo espetáculo de uma claraboia iluminada, agitada por um movimento de imagens, geralmente em cores, sobre a qual se fixam com uma atenção evidente os olhares de seres geralmente assentados e imóveis. Talvez ainda não se tenha mensurado a revolução civilizacional inerente a esse objeto técnico, condicionado pela energia elétrica, que encontrou lugar nos quatro cantos do planeta, nos apartamentos de Nova Iorque ou nas favelas do Cairo, nas escolas da Patagônia ou nos hotéis de luxo de Bangkok. De uma banalidade desarmante, tendo sido objeto de poucas inovações do ponto de vista de seu design, o televisor, tornado hoje tela plana, constitui, no entanto, um dos móveis mais visíveis, mais valorizados, na maior parte dos espaços habitados privados e cada vez mais públicos. Ele constitui no coração do lar, ao mesmo tempo um espaço de intimidade e repouso, sinônimo de ruptura com o trabalho, e um espaço de frenesi, aberto para o lado de fora, em ligação com o mundo, fonte de relações, de eventos e de palavras que nos arrancam de nosso meio, tornado sessão a portas fechadas do social. Em termos mitológicos, aqueles da Grécia Antiga, a televisão é bem uma encarnação mista de Héstia, deusa do lar, e Hermes, divindade dos contatos, da circulação e das trocas.

Primeiro agente de circulação de informações e de mundialização dos hábitos, a TV suscita um conjunto quase ritual de comportamentos uniformes ${ }^{1}$, quaisquer que sejam os ambientes culturais e as mensagens visuais: disposição da mobília para favorecer uma experiência de percepção de um espetáculo, assembleia de espectadores orientados em direção da fonte luminosa, horários estipulados para um espetáculo programado geralmente com hora fixa (jornal de notícias, novela, competição esportiva), silêncios ou trocas verbais ditadas pela imagem-som do receptor etc. 0 prazer primário, sem contar os benefícios secundários, ligado a essa situação em que se entremeiam o ritual dos corpos fixos, liame social de comunhão em uma mesma experiência como sublinharam Daniel

${ }^{1}$ Sobre essa ritualização, ver a análise de Mihai Coman (2003, p. 37-44). 
Dayan e Elihu Katz (1996), e sobretudo, a contemplação de uma imagem que irrompe de um outro lugar, colocam em dúvida a recondução a uma pulsão lúdica de divertimento. Não se estaria mais perto da compreensão invocando uma estrutura emotivo-cognitiva como aquela do numinoso, para retomar a expressão de Rudolf Otto (2001), que subjaz precisamente às condutas religiosas?

A TV lembra de fato mais uma hierofania, uma manifestação do sagrado, com a imagem bloqueada num quadrado vertical fechado, que não é mais do que o deslocamento de $90^{\circ}$ de um local de adoração horizontal, o lugar da cratofania (enquanto manifestação de uma potência transcendente). A tela aninhada na casa, presa na parede, parece mesmo um tipo de altar em que surge uma imagem dotada de um mana, de uma força mágica transcendente, que irrompe no profano e no cotidiano. A antena universal exterior, que marcou longamente a história técnica desse meio, não desempenha o papel de um "axis mundi" (ELIADE, 1987), de um pilar intermediário que liga, como nas crenças tradicionais, alto e baixo, céu e terra, captando ondas invisíveis, sobrenaturais? 0 evento que é a imagem sobre o televisor abre, assim, um espaço-tempo no interior do mundo familiar ou doméstico em que o homem reencontra inconscientemente os comportamentos religiosos mais arcaicos. A energia portadora, transportadora da imagem, é de todo modo da mesma ordem que os fluidos cósmicos que utilizam as potências invisíveis para circular no mundo. Fazer funcionar o televisor é como um rito em que se acende a luz sagrada através da qual o fiel chama seu deus. 0 olho e o ouvido se colocam então em posição de passividade, de receptividade ou de recolhimento como diante de uma epifania sagrada. De toda maneira, a invenção técnica da TV tem o mérito de animar a imagem, de fazê-la viva, restituindo à imago Dei uma força de presença incomensurável em relação à fotografia fixa, à estatueta ou à estátua. Com a imagem eletrizada, a encarnação do divino faz a vida sobrenatural passar da subjetividade da crença à objetividade da mostração. Não é mais necessário crer na presença do que está além da representação porque a representação se faz ela mesma simulacro de presença. Esta exteriorização e esta subjetivação da consistência viva da imagem explica, talvez, a passividade crônica do fiel telespectador. 0 sagrado da aparição não precisa mais de uma mudança interior que torna a imaginação do crente receptiva, porque a tela se anima por si mesma sem esforço. É por isso que a imagem televisual acarreta uma espécie de sideração, de catatonia de todo o ser que assiste ao desenvolvimento das aparições, ao ponto de tornar-se inerte, insensível ao conteúdo mesmo das imagens, que se parecem todas do mesmo modo que as diferentes aparições da mesma 
potência sagrada. Detemo-nos então diante do aparelho como detemo-nos diante da face da onipotência.

Mas esta imagem viva de uma alteridade sagrada não é mais, para dizer a verdade, tratada somente como meio. Enquanto a imagem hierofânica coloca em contato o fiel com o deus ausente, a imagem televisual se toma por uma automanifestação última. Não se venera mais aquele que é representado, mas se adora aquele que se faz presente, ou seja, a imagem em si, que se revestiu com os atributos do divino. 0 mistério técnico de uma imagem que se anima sem referente se torna fonte de uma magia de presença pura, sem mediação. Liberando-se de toda a função de signo, a imagem, em seu fluxo permanente, opera então como uma forma presente cuja potência vem de sua mostração e de seu movimento interno, de sua perpetuação na tela. Vestígio, sem dúvida, de uma crença ingênua e mágica, que erroneamente se atribuiria a um público frustrado e ignorante. 0 gênio da técnica televisual é conseguir provocar e capturar toda consciência, que se presta assim a uma irresistível ilusão e autossugestão.

Então, pode-se ligar o fenômeno do consumo televisual a um avatar do rito religioso, no sentido em que ele organiza o vivido dos homens em torno de manifestações repetitivas, de potências invisíveis, em meio a comportamentos regrados, inseridos em ciclos temporais, localizados em espaços protegidos e valorizados. Certamente, se o sagrado no religioso tradicional assegura antes de tudo uma função de relação e de mediação com o mundo sobrenatural, a imagem TV se vê enfim sacralizada, divinizada ela mesma, deslizando em direção a uma forma de fetichismo ou de religiosidade sem Deus. 0 tempo de contato com a imagem constitui um tempo intenso, que se arranca do peso das coerções externas e que se torna fonte de excitações e interiorização de emoções - de alegria ou tristeza. 0 psiquismo do homem TV é dominado por um vivido participativo através do qual a imagem ativa emoções, acumula experiências de imagens. A imagem coloca cada um em contato com um grande inventário de seres distantes, mas que irrompem em nossas vidas. Fonte de projeção e de identificação, a imagem oferece ao Ego uma socialidade por procuração que o torna contemporâneo de todos os seres múltiplos que animam a tela. Esta religação empática com mundo da representação imajada se duplica em socialidade inter-humana modificada. A participação vertical na imagem pode, de todo modo, a seu turno, ser partilhada por outros no mesmo lugar ou desembocar em uma espécie de vivido comum que se encontra religado pelo comentário social dos jornais especializados, as narrativas induzidas que nutrem as trocas do tempo familiar ou do mundo do trabalho. A televisão, impondo-se como um 
referencial comum de uma sociedade, malgrado a multiplicidade de programas, se transforma assim em uma vulgata em que os heróis e os grandes feitos se tornam uma espécie de fundo comum do mito social. Da escola à casa de repouso, do escritório à cantina, as epifanias da vigília, saturada de imagens, servem de matéria-prima ao grande discurso que produz o ruído de fundo da socialidade.

\section{Uma religiosidade truncada}

Ocorre que, sobre esse pano de fundo da socialização, a TV engendra também o efeito perverso de uma insensível dessocialização que a conduz sobre a via de uma religiosidade fragmentada. Sob certos aspectos, a proliferação das telas individuais isola a imagem religiosa, e por isso a TV segue ou acompanha o processo geral de individualização da vida social contemporânea. Diante de sua tela, o espectador é fechado em um cara-a-cara com a imagem, ainda mais que o tamanho da imagem predispõe ao isolamento em um espaço restrito. Entre os olhos e a imagem se amplia uma bolha, que é a fonte da fascinação sagrada, mas que rejeita, como no exterior, toda presença ressentida enquanto intrusa. A relação televisual acaba assim, às vezes, em narcisismo, ou em autismo, condenando à deriva patológica essas crianças drogadas por horas ininterruptas de transmissões e, hoje, à Internet ou jogos de vídeo. Nesse sentido, a reclusão no espaço-tempo mágico da imagem animada corre o risco de favorecer uma dessocialização latente ${ }^{2}$, contrária às funções de integração dos fenômenos religiosos.

De modo mais dissimulado ainda, o aumento da duração da visão, a insensibilização crescente ao outro, acarretada pela simulação da presença na tela, podem terminar privando o sujeito de toda atenção ao outro. O hábito tornado vício e em seguida dependência rebaixa o sentido de vigilância ao próximo e faz de todo outro um alter ego de uma imagem que se torna presente sem precisar de encontro. A imagem na tela não solicita nem resposta, nem adaptação, nem respeito. Torna-se tentador, então, transformar o ambiente vivido em tela de televisão e assimilar a do outro, a palavra do outro, em outros lugares e circunstâncias a essa superpresença que não obriga a nada. Nesse sentido, o abuso da experiência TV enfraquece o sentido do outro e favorece na vida real a indiferença ou a grosseria social. Quantas pessoas se comportam em assembleia, em uma aula, em um espaço público como se os presentes não fossem mais do que um cenário animado na tela? Assim, a

${ }^{2}$ Breton (2000) faz uma análise similar a propósito da Internet. 
dependência da TV que nos faz participar da sociedade ilimitada nos faz perder também, por vezes, as condições-limite da sociabilidade. Fraqueza, sem dúvida, inerente ao rito em si, que começa e para sem restrição simbólica e que dissolve a fronteira entre real e imagem, entre o vivido comprometido e o vivido simulado. A religião do sistema TV nutre um mundo comum que ele regenera cada dia em emoções e narrativas, que ele fixa por uma participação mediúnica particularmente marcante, mas que pode também fazer os indivíduos perderem o peso das obrigações pelas quais se constrói um mundo comum, porque ele repousa sobre um rito de fascinação que leva à autossuficiência. Assim, a dependência televisual se revela frágil e arrisca-se a reduzir o outro a um cúmplice de uma experiência autista ou a um dublê de um ser imajado, cuja presença não é acompanhada de nenhum contrato social.

\section{A experiência demoníaca}

Se o sistema TV reativa, então, experiências do sagrado e do religioso, isso não ocorre sem riscos, como o religioso em si. A esfera do religioso não pode se reduzir, de fato, apenas à relação positiva entre o homem e o sobrenatural, fonte de bondades e recompensas, obtidas ao fim de preces e oferendas. 0 religioso, através da ambivalência do sagrado, comporta também uma face mais sombria, inquietante, feita de contato com forças sobrenaturais hostis, nefastas, ou de transformações de si temíveis, em que se perde a própria identidade para se assimilar ao invisível. A TV não participaria, também, dessas funções magico-ocultistas do religioso, que se conectam ao demonismo? A TV não teria, também, sua face de sacralidade obscura, transgressiva, demoníaca?

Não se deixou de recordar, desde Platão, as conivências entre imagem e mentira, já que ela faz crer, geralmente, que uma aparência equivale ao ser, que uma representação iguala seu modelo. A complacência a respeito das imagens é, então, a marca de uma inclinação à falsidade, ao engano, à falácia. Deste ponto de vista, a imageria televisual não apenas levou ao extremo esta confusão entre imagem e realidade representada, mas em função de a consciência mágico-religiosa favorecer sua recepção, ela pode ser acusada de ter instituído em nossas vidas mais as armadilhas, a mistificação ao ponto de fazer desaparecer toda consciência crítica, como em um feitiço. Nesse caso, a TV não seria somente uma das inúmeras fontes de engano das consciências que agitam o teatro de sombras da cidade, denunciadas já por Platon (2016) ou Bacon (2010), mas se aparenta frequentemente a um 
ritual de possessão, ou seja, de despossessão de si, de provocação de estados de consciência alucinada, de estados segundos, vizinhos do transe.

0 próprio da técnica da TV é difundir uma diversidade de produtos imajados que não tem o mesmo coeficiente de artifício, o que impede todo julgamento global. A transmissão de um filme não é equivalente à de uma reportagem sobre um evento real, um clipe musical não é comparável à transmissão de um ofício religioso, um debate ao vivo não é uma reconstituição por imagens de uma síntese de catástrofe natural. No entanto, plugando-se uma tela, faz-se na maior parte do tempo surgir uma imagem, livre de toda identificação. A ausência de qualquer indicação sobre a natureza da imagem, que desempenharia o papel de legenda de uma ilustração (desenho, fotografia em livro), conecta esse meio imediatamente a um sistema técnico que joga com a surpresa e a ilusão (e essa última parece acentuada com essa hibridação que se opera a partir da pequena tela: documentários-ficções ou, ao contrário, ficções documentais³). Mesmo que a palavra ou o texto permitam, geralmente, de modo sequencial, determinar a natureza realista ou ficcional do produto-imagem, a verdade é que o telespectador tem prazer nessa desorientação, nessa suspensão da verdade, e que a imagem, por sua animação à altura dos olhos, tem o poder da fazer esquecer sua natureza e sua identidade de imagem. Não é de espantar que se possam imputar ao hábito desse meio as confusões patológicas do real e do imaginário, resultando em passagens do fantasma ao ato. Mas, dessa maneira, a TV não faria mais do que transportar a domicílio e multiplicar de modo repetitivo as seduções do espelho, os maravilhamentos da câmera obscura, as fantasmagorias dos prodígios estrangeiros da sociedade pré-moderna. Mas então não seria, por outros meios, o prolongamento do gosto pelo maravilhoso e do prazer de ser atraído por técnicas de produção de ilusões? Ou de um avanço cada vez mais impulsionado, embora silencioso, da hipnose cotidiana de consciências, semelhante ao consumo narcótico, presente em rituais iniciáticos das sociedades politeístas?

Talvez seja necessário ir mais longe e descobrir por trás do jogo de farsas da imagem uma experiência mais inquietante, pois frequentando-se assim a imagem sobre as telas pequenas se está exposto a tentações e seduções das quais não se sai impune. Pois atrás da imagem graciosa e visível se esconde, por vezes, uma maliciosa que insinua em nós uma falsa crença para nos enganar. Mesmo que não se deva generalizar a exceção, a verdade é

\footnotetext{
${ }^{3}$ François Jost (2004, p. 57-83) sublinha assim esta tendência das séries televisivas a criar "a terra sem gênero, na qual uma imagem poderia pertencer tão bem a uma reportagem quanto a uma série".
} 
que a imagem na TV, como a imagem cinematográfica, e mesmo a imagem fotográfica é quase sempre uma imagem fabricada, decupada, montada, organizada, linearizada de modo artificial. Exemplos notórios permitiram sensibilizar o público ao verdadeiro-falso dos documentos visuais ${ }^{4}$ que abusam da credibilidade da imagem junto a um espectador tornado crédulo. Sob uma forma mais benigna, quantas informações sobre eventos bem datados são acompanhados de imagens de arquivos cujo caráter desatualizado é frequentemente mascarado. Em todos esses casos, jornalista, técnico, produtor usam o meio televisual para adormecer o espírito crítico e despossuir o público de todos os meios de identificar a imagem e chegar à verdade. O sistema da TV leva então a desenvolver estratagemas para mascarar o verdadeiro no momento em que ele é entendido por imagem, o mais naturalmente, o mais incontestavelmente desvelado. Longe do jogo agradável, a enganação se torna aqui falta, malícia diabólica propriamente dita na medida em que instila deliberadamente o falso no verdadeiro e, portanto, o mal no bem. Sobre a tela de uma televisão, crê-se, às vezes com confiança, encontrar o real mais adequado, mais fiel, enquanto a imagem é deliberadamente trucada ou falsificada. Desde então, é verdade que a visão na TV se aproxima de um rito sagrado o qual se torna, em certos casos, relação com forças ocultas que provocam uma desestabilização do sujeito, uma perda de identidade do $\mathrm{Eu}$, que não estão longe de levar a pensar em ritos de possessão por seres maléficos. No registro mítico do monoteísmo, a tela da TV pode se tornar ocasião de uma sorte de enfrentamento de Satã, esse espírito que se apossa de nossa liberdade para nos fazer crer no falso. Resulta, se vai até o fim da hipótese, que o sistema TV institui na religião da imagem sucedâneos de ritos de possessão de espíritos, facilitados pelo dogma geralmente disseminado de que a TV diz a verdade, precisamente porque ela mostra o que diz. Não é, então, surpreendente que o público da televisão se divida em categorias bem tipificadas: os espíritos crédulos e simples, presas fáceis de capturar pelo sortilégio das falsas imagens; falsos espíritos fortes, que creem estar prestes a encontrar o diabo, esquecendo que ele se disfarça para melhor agir; espíritos céticos, enfim, que pressentem as armadilhas da claraboia, desconfiados e irônicos ao ponto de crer que tudo é falso. Panóplia clássica das populações religiosas, inventário convencional das atitudes de crença. A força do impacto do meio, malgrado todas as garantias deontológicas e todos os controles democráticos, reside

\footnotetext{
4 Pensamos especialmente na falsa entrevista de Fidel Castro por Patrick Poivre d'Arvor, denunciada entre outros por Ignacio Ramonet em La tyrannie de la communication (2001).
} 
talvez nessa possibilidade permanente de mistificação pelo simulacro, que às vezes atinge os limites da alienação do destinatário.

\section{A liberação pelo maravilhamento mágico}

Esse risco que poderia levar a erradicar o instrumento do mal, liberando as consciências do empreendimento cotidiano da mentira (e sabe-se como a diabolização da TV pode ser uma tentação das autoridades religiosas fundamentalistas), é, no entanto, grandemente compensado por uma experiência oposta em que a magia negra da estação de TV se muda em magia branca, em conquista de um poder quase sobrenatural sobre a ordem das coisas. De fato, se a imagem pode enganar, ela age também como um multiplicador fantástico de nossa potência visionária, como um transfigurador de nossa finitude ${ }^{5}$. Esta é a origem do fascínio pela televisão ao vivo. Através da técnica de registro e difusão de imagens instantâneas, nosso olho e nossas emoções se encontram em contato direto com as catástrofes naturais, eventos políticos, guerreiros, esportivos, mas também com os grandes eventos cerimoniais (casamentos reais etc.) em que o discurso de rotina dos jornalistas se encontra subitamente dominado por figuras do pensamento simbólico (COMAN, 2003; DAYAN; KATZ, 1996), acentuando o caráter ritual ou mítico da TV. Sem ação, sem esforço, eis-nos contemporâneos, testemunhas do que se passa distante de nós, um dos símbolos mais significativos sendo a visão dos primeiros passos de Neil Armstrong sobre a lua em 1969 por milhares de telespectadores. Conferindo-nos o dom da ubiquidade, a imagem nos permite tanto ver sem riscos, seguir um combate em segurança, quanto ver até melhor que se estivéssemos lá. A imagem televisual se torna assim um olho artificial que remove os obstáculos do tempo, do espaço e também dos medos, das penas e dores próprias à vida real, inevitáveis se estivéssemos presentes no coração do evento. Vivemos assim uma espécie de crescimento cósmico, temos acesso a um tipo de visão panorâmica, sinóptica, integral, que no fundo não era nada senão o privilégio dos xamãs visionários ou mesmo dos deuses que tudo veem. 0 telespectador que se encontra, no tempo de um jornal de notícias, transportado através dos continentes, confrontado com os dramas e alegrias da humanidade, atinge uma espécie de plenitude ontológica, acompanhada de um tipo de saber absoluto que o faz deixar seu corpo e cavalgar através do espaço e do tempo. Pela coleta de

\footnotetext{
5 "Nosso mundo hipertecnologizado é essencialmente mágico. Por um mecanismo qualquer a fronteira entre realidade e fantasia é transgredida permanentemente. Para os gêneros artísticos e documentários da televisão, a plausibilidade, a verossimilhança e a anulação da desconfiança são as principais ambições e principais vitórias. Nesse sentido, a televisão aparece como o mágico supremo, o mestre do 'como se' na cultura contemporânea.” (SILVERSTONE, 1988, p.27).
} 
imagens no mundo, por seu desfile sucessivo e às vezes cíclico sobre a tela, tornamo-nos, fantasmaticamente, mestres do mundo, sentados em nosso sofá. A imagem sagrada se torna desde então como que um instrumento de liberação de nosso corpo, projetando-nos em uma esfera de representação em que temos acesso a uma panvisão. Próximo das experiências à base de alucinógenos, o fenômeno TV se aparenta a uma espécie de viagem xamânica para além das fronteiras da vida finita e nos entrega visões que propriamente falando são impossíveis. A religião TV permite a seus adeptos injetar em sua existência mundos distantes, proibidos na vida cotidiana, cujo espetáculo não pode senão aumentar o sentimento de potência do eu. 0 espaço televisual se transforma assim em cabana iniciática onde, ao abrigo do mundo, a alma supera todos os seus limites encarnados e se alça ao plano dos seres divinos.

Assim, o sistema TV parece ser tanto uma religião truncada como uma síntese de todas as experiências sagradas experimentadas pelas religiões mono ou politeístas, prova que a suposta dessacralização suposta da qual a técnica participaria pode às vezes engendrar uma paradoxal e simultânea ressacralização (WUNENBURGER, 2010). As imagens na tela, com a cumplicidade ativa ou passiva dos manipuladores de imagem, nos fazem reviver a hierofania do deus, das situações de possessão maléfica, de transformações de si no sentido de uma autodivinização. Certamente, esses modelos culturais de interpretação podem exceder a banalidade do fenômeno, eles não são nada menos do que tipos-ideais que permitem melhor compreender o impacto desse encontro ritual cotidiano com imagens na tela. Como compreender que milhares de homens possam - às vezes quase simultaneamente, quando de eventos mundiais - abandonar a vida para se prostrar em um sofá, para se deixar enfeitiçar por imagens animadas, se não se pesquisa atrás das rotinas e das motivações evidentes uma espécie de necessidade arcaica que foi até agora dominada e explorada pelos ritos e mitos religiosos? Nesse caso, seria mais sábio compreender, ao contrário, o destino das religiões a partir desse espelho que ao mesmo tempo amplia e deforma que é a indústria da TV que chega, sem que nenhuma intenção global tenha sido jamais formulada, a sintetizar os grandes componentes das experiências religiosas até quase adquirir seu monopólio. Talvez o homem contemporâneo esteja em vias de inventar uma nova religião, que toma o meio pela mensagem, de acordo com a teoria de Marshall McLuhan (1968), e a imagem pelo sobrenatural em si. E talvez se possa pensar, inversamente, que o despertar das religiões tradicionais passará por uma crítica e uma reapropriação da TV, apreendida como seu mais audacioso concorrente e simulacro. 


\section{Agradecimento}

O autor agradece calorosamente Céline Bryonportet por sua leitura, suas sugestões felizes e seus complementos bibliográficos.

\section{Referências}

ADORNO, Theodor; HORKHEIMER, Max. La production industrielle de biens culturels: raison et mystification des masses. In: ADORNO, Theodor; HORKHEIMER, Max. La dialectique de la raison. Paris: Gallimard, 1974. p. 129-176.

BACON, Francis. Novum organum. Paris: PUF, 2010.

BRETON, Philippe. Le culte de l'internet: une menace pour le lien social? Paris: La iDécouverte, 2000.

COMAN, Mihai. Pour une anthropologie des médias. Grenoble: Presses universitaires de Grenoble, 2003.

DAYAN, Daniel; KATZ, Elihu. La télévision cérémonielle. Paris: PUF, 1996.

DEBRAY, Régis. Vie et mort de l'image: une histoire du regard en occident. Paris: Gallimard, 1989.

ELIADE, Mircea. Le sacré et le profane. Paris: Gallimard, 1987.

JOST, François Jost. Séries policières et stratégies de programmation. In: BEYLOT, Pierre; SELLIER, Geneviève (Orgs.). Les séries policières. Paris: L'Harmattan, 2004.

MCLUHAN, Marshall. Pour comprendre les media: les prolongements technologiques de l'homme. Paris: Seuil, 1968.

OTTO, Rudolf. Le sacré: l'élément non-rationnel dans l'idée du divin et sa relation avec le rationnel. Paris: Payot, 2001.

PLATON. La république. Paris: Flammarion, 2016.

RAMONET, Ignacio. La tyrannie de la communication. Paris: Gallimard, 2001.

SILVERSTONE, Roger. Television, myth and culture. In: CAREY, James W. (Org.). Media, myth and narratives. Londres: Sage publications, 1988.

WUNENBURGER, Jean-Jacques. Le sacré. Paris: PUF, 2010. 


\title{
The screens of the sacred or the religious imaginary of television
}

\begin{abstract}
This article aims to present the hypothesis that the success of television comes from its effectiveness in taking the place of the religious, consolidating itself as a point of re-encounter with the sacred, but without a god, anthropocentered: a selfmanifestation. This hypothesis is investigated through philosophical methodology. It is concluded that, instead of mobilizing communion, characteristic of the integration of religious phenomena, television promotes isolation, resembling a truncated religion, a synthesis of all sacred experiences. This finding contradicts the supposed desacralization provided by the technique, engendering a paradoxical and simultaneous resacralization. The images on the screen revive the hierophany of the god, from situations of evil possession, from selftransformations towards self-divination.
\end{abstract}

\section{Keywords}

Television. Imaginary. Media religiosity. Resacralization.

\section{Les écrans du sacré ou l'imaginaire religieux de la Télévision}

\section{Résumé}

Cet article présente l'hypothèse où le succès de la télévision est dû à son efficace prise de la place des religieux, consolidant ainsi sa position de point de réunion pour le sacré, mais sans Dieu, anthropocentrique : une auto-manifestation. En conclusion, au lieu de mobiliser la communion, caractéristique de l'intégration des phénomènes religieux, la télévision favorise l'isolement, en constituant une espèce de religion tronquée, une synthèse de toutes les expériences sacrées. Cette conclusion contredit la désacralisation accordée par l'art, mettant l'accent sur la génération d'une résacralisation paradoxale et simultanée. Les images sur l'écran ravivent I'hiérophanie, les situations de possession du mal, les transformations de soi vers l'autodivinisation.

\section{Mots-clés}

Télévision. Imaginaire. Religiosité mediatic. Resacralisation.

Recebido em 03/04/2017

Aceito em 01/05/2017 